УДК 32.019.51

MAMAEBA Юлия Александровна - кандидат исторических наук, доцент; доцент департамента политологии факультета социальных наук и массовых коммуникаций Финансового университета при Правительстве РФ (125993, Россия, г. Москва, ГСП-3, Ленинградский пр-кт, 49; aтеliya-ат@ rambler.ru)

РОДИОНОВА Марина Евгеньевна - кандидат социологических наук, доцент; доцент департамента политологии факультета социальных наук и массовых коммуникаций Финансового университета при Правительстве РФ (125993, Россия, г. Москва, ГСП-3, Ленинградский пр-кт, 49; MERodionova@fa.ru); директор no PR u GR Celebrium-Labs

\title{
ПРИМЕНЕНИЕ PR-TЕХНОЛОГИЙ КАК ДЕЙСТВЕННЫЙ ИНСТРУМЕНТ ДЛЯ СОХРАНЕНИЯ ИСТОРИЧЕСКОЙ ПАМЯТИ
}

\begin{abstract}
Аннотация. В данной статье рассматриваются вопросы, связанные с применением PR-технологий в ходе деятельности, связанной с сохранением исторической памяти стран и традиционных представлений. В материале исследуются особенности превентивных мер со стороны правительств и иных акторов в отношении действий, направленных на ослабление единства общественного мнения по ключевым вопросам истории рассматриваемых стран. Проводится анализ эффективности методов и конкретных действий, применимых и совершенных в этом направлении, в части их влияния на умонастроения социальных групп, определяемых для реализации PR-технологий в целях сохранения исторической памяти. Ключевые слова: историческая память, PR-технологии, позитивная повестка, общественное сознание, национальная безопасность
\end{abstract}

$\mathrm{P}$ ассмотрение проблематики применения $P R$-технологий в ходе непрекращающейся дискуссии вокруг исторических аспектов существования и развития различных стран в настоящее время требует определить основные направления деятельности политических акторов по использованию технологий. Различный инструментарий, который по своим сущностным характеристикам подпадает под определение $P R$-технологий, использовался задолго до появления данного термина [Цуканов, Цуканова 2016]. Указанная особенность не опровергает значительного развития методов и способов воздействия в ходе выстраивания связей с общественностью и их применения для требуемой корректировки вектора развития исторической памяти как совокупности представлений ядра общества об основных аспектах истории страны.

\section{К вопросу о понимании термина «историческая память»}

Исследуя вопрос о сохранении исторической памяти в контексте применения $P R$-технологий, необходимо заострить внимание на понимании термина «историческая память» в части его оценки со стороны различных политических акторов. Данный термин в значительной степени сходится с историческим нарративом, принимаемым большинством населения страны, содержание которого может рассматриваться в качестве элемента национальной традиции. При этом стоит отметить, что такая «эталонная» историческая память не может существовать в рамках одного описанного источника, как, например, предлагалось в рамках Краткого курса истории ВКП(б), предполагавшего единственно верный взгляд на определенный исторический этап жизни страны в рамках деятельности одной из политических партий, впоследствии ставшей правящей и дублировавшей полномочия 
органов государственной власти, предусмотренных законодательно [Сталин 1938]. Однако даже указанная работа, не предлагавшая при этом универсальный взгляд на историю страны и распространявшаяся при помощи наиболее эффективных на тот момент $P R$-технологий, не смогла сформировать принятый большинством населения исторический нарратив в отношении рассматриваемых в работе событий.

Исходя из этого возможно восприятие исторической памяти как неустойчивого в своем содержании исторического нарратива, принимаемого большинством населения страны, в котором, однако, существует неизменно общее восприятие ключевых событий в ее истории. Это позволяет говорить о существовании национального сознания и, соответственно, о субъектности страны, выраженных в наличии внешних атрибутов, присущих большинству образований, которые обладают признаками государственности. В связи с этим значение исторической памяти и борьба за ее сохранение влекут за собой участие значительного числа основных политических акторов в процессах, так или иначе с ней связанных. В качестве данных акторов следует рассматривать прежде всего государства, а также иных политических акторов, способных оказать влияние на общественное сознание через использование $P R$-технологий для воздействия на историческую память. При этом их круг расширяется вместе с общим развитием политических технологий в мировой политике [Булавин и др. 2018].

Основное внимание политических акторов направлено на наиболее восприимчивые к предлагаемому историческому нарративу группы населения. При этом потенциальный круг указанных групп для государства (правящей элиты) и иных участников политического процесса в значительной степени различается. Правящие элиты сталкиваются с необходимостью применения $P R$-технологий в отношении подавляющего большинства населения, что обусловлено необходимостью поддержания стабильности гражданского общества в целях сохранения существующего положения. Политические акторы, находящиеся в оппозиции к действующей власти или реализующие интересы, отличные от интересов власти, имеют возможность выборочно использовать $P R$-инструментарий для негативного воздействия на действующую систему исторических ценностей и, соответственно, нанесения урона существующему политическому режиму.

Следует предположить, что вышеназванная проблематика использования $P R$-технологий для воздействия на преобладающий исторический нарратив наиболее актуальна для стран с одной политической силой, доминирующей на протяжении значительного числа лет, что позволяет четко разделить модели поведения государства и его «официальной» исторической памяти и иных политических акторов, предлагающих альтернативные или значительно отличающиеся версии национальной истории.

Страны, чьи политические системы обладают развитой системой политических партий, устоявшимися общественными институтами и сложными механизмами поддержания связей с общественностью, имеют ограниченный круг вопросов, относящихся к наиболее острым моментам исторического нарратива, что позволяет правящей элите (в значении правящей политической силы) ориентироваться на группы населения, рассматриваемые ею в качестве потенциальных избирателей. Иными словами, жесткая централизация власти и ее сосредоточение в руках одной правящей группы приводит к необходимости поддержания наиболее благоприятного для нее исторического нарратива в качестве единственно верного или приоритетного для большинства населения страны. Также данная задача стоит перед странами 
(преимущественно перед действующей в стране властью), занимающими переходное или промежуточное положение в географическом, политическом, религиозном, цивилизационном и иных аспектах. В качестве примера вышеназванных стран, как представляется, можно рассматривать Россию, Турцию, Иран, Египет, отчасти КНР и ряд других стран, обладающих схожей внутри- и внешнеполитической конъюнктурой, обусловленной перечисленными аспектами.

\section{$\boldsymbol{P R}$-технологии общественного восприятия исторических событий}

Затрагивая особенности противостояния в сфере борьбы за историческую память, допустимо обратиться к действиям политических акторов, в которых прямо или косвенно применялись $P R$-технологии и объектом которых являлось общественное восприятие исторических событий. Опираясь на вышесказанное, особое внимание стоит уделить России как стране, сочетающей в себе различные по своему направлению цивилизационные особенности, что в значительной степени влияет на степень внимания, уделяемого вопросам сохранения исторической памяти, и приводит к многочисленным проявлениям активности в данной сфере со стороны наиболее влиятельных политических акторов. Наибольший интерес отводится вопросам, связанным с восприятием истории XX в., а именно событиям, относящимся ко Второй мировой войне и особенно событиям Великой Отечественной войны, являющейся ее неотъемлемой частью. На примере общественной дискуссии о Великой Отечественной войне возможна наглядная иллюстрация применения $P R$-технологий.

Вопрос о сохранении исторической памяти о Великой Отечественной войне рассматривается российским руководством как один из основных, что особо подчеркивается вниманием, которое уделяется данному направлению президентом РФ В.В. Путиным. Следует уделить внимание наиболее важному событию из «плановой» политической жизни России, т.е. посланию Президента Федеральному собранию. В ходе своего выступления в 2020 г. президент заявил о необходимости «защитить правду о Победе», подчеркнув важность противодействия распространению лживой информации и «попыткам переиначить историю» путем противопоставления фактов. Речь идет об использовании $P R$-технологий, что в настоящий момент активно реализуется государством через современные информационные технологии, составляющие основу инструментария для организации связей с общественностью1. При этом характерным является последовательное возвращение В.В. Путина к теме Второй мировой войны на протяжении всего периода его правления, что, с одной стороны, подчеркивает важность указанных событий для страны, а с другой - говорит о значимости вопросов, связанных с восприятием исторического нарратива населением, и, соответственно, необходимости поддерживать его благоприятное с политической точки зрения развитие [Денисов 2019].

Представленная ситуация в значительной степени вовлекает подавляющее большинство политических акторов России, что порождает значительное число событий в сфере сохранения исторической памяти и формирования исторического нарратива о Второй мировой войне, которые зачастую приводят к конфликтам. Участвующие в них стороны возлагают большие надежды на возможности рассматриваемого инструментария $P R$-технологий.

1 Послание Президента Федеральному Собранию в 2020 году. Доступ: http://kremlin.ru/ events/president/news/62582\#sel=109:23:hha,109:25:ahh (проверено 25.08.2020). 


\section{Кейс храма Воскресения Христова как главного храма Вооруженных сил Российской Федерации}

При этом именно 2020 г. стоит рассматривать в качестве временно́го отрезка, в ходе которого применение данных технологий для воздействия на общественное восприятие исторических событий представляется наиболее масштабным по числу информационных поводов и общему уровню ожесточенности дискуссии, что обусловливается как юбилейной датой Победы в Великой Отечественной войне, так и существующей конъюнктурой. Широкое внимание общественности привлек храм Воскресения Христова, который позиционировался его создателями и фигурировал в СМИ как главный храм Вооруженных сил РФ, построенный в ознаменование 75-й годовщины Победы. В рамках вышеназванного кейса возможно отметить противоборство множества политических акторов России, стремившихся использовать новые смыслы, создаваемые при строительстве храма, для воздействия на восприятие населением массива исторической памяти о Великой Отечественной войне и последующей реализации своих политических интересов. С одной стороны, следует отметить позитивные оценки проекта, акцентировавшие внимание на роли главного храма Вооруженных сил в деле воспитания молодежи и повышения общего уровня морали населения путем синтеза религии и одного из наиболее почитаемых событий в российской истории [Петрий 2019]. Также подчеркивается существование традиции, предполагавшей возведение культовых религиозных построек, что нашло свое отражение в данном проекте и может считаться «показательным примером реконструкций дореволюционных мемориальных практик». Наиболее ярким примером является постройка храма Христа Спасителя как главного памятника событиям Отечественной войны 1812 г., которая, в свою очередь, коррелирует с его восстановлением после распада Советского Союза [Аникин 2020]. С другой стороны, значительное число критиков подчеркивают существование множества спорных моментов, которые могут привести к негативным последствиям для позитивного восприятия исторического нарратива о Великой Отечественной войне вследствие отрицательного $P R$-эффекта от особенностей архитектуры и убранства храма, а также в связи с отрицательным информационным фоном вокруг процесса его постройки. Неоднозначным решением возможно признать использование музейных экспонатов в виде элементов немецкого вооружения при возведении ступеней храма Воскресения Христова ${ }^{1}$, которые, по замыслу создателей, должны играть роль мощного $P R$-инструмента, подчеркивающего победу над противником и положительно воздействующего на сознание посетителей. Однако, как представляется, данный шаг вступает в противоречие с необходимостью сохранения исторического наследия, к которому в т.ч. относится и трофейное немецкое вооружение. Это дает возможность противникам существуюшего и поддерживаемого государством исторического нарратива говорить об этом шаге как о действиях, десакрализующих идею сохранения исторической памяти для потомков и подчеркивающих стремление к внешнему эффекту в ущерб внутреннему содержанию объекта. Определенные вопросы у части общественности и СМИ вызвало внутреннее оформление храма ${ }^{2}$, содер-

\footnotetext{
1 Фашистскую сталь пустили на храм. Доступ: https://pobedarf.ru/2020/03/14/84764798am/ (проверено 03.07.2020).

2 Главный храм Вооруженных сил РФ открыли в Подмосковье. Что увидят прихожане? Доступ: https://novayagazeta.ru/articles/2020/06/23/85980-glavnyy-hram-vooruzhennyh-silrf-otkryli-v-podmoskovie-chto-uvidyat-prihozhane (проверено 03.07.2020); Под Москвой открыт главный храм российской армии. Чем он успел прославиться? Доступ: https://www. bbc.com/russian/news-53020701 (проверено 03.07.2020).
} 
жащее в себе как традиционные религиозные элементы, так и изображения батальных сцен, советскую символику и портреты государственных деятелей. В определенной степени это может трактоваться как вызов канонической традиции и нарушить планируемую гармонию между религиозным и светским началами, призванную обеспечить сохранение исторической памяти.

Наиболее значительным кейсом, связанным с вопросами сохранения исторической памяти о Великой Отечественной войне и применением $P R$-технологий, можно считать опрос, проведенный оппозиционным телеканалом «Дождь» в 2014 г., посвященный теме блокады Ленинграда и целесообразности его обороны. Данный опрос был крайне негативно воспринят в обществе и привел к негативным правовым последствиям в отношении телеканала, а также нанес существенный урон российской оппозиции, в значительной степени лишив ее возможности опираться на патриотическую повестку [Романов, Романова, Морозова 2015]. Противниками российской оппозиции был также активно использован резкий комментарий российского политического деятеля А.А. Навального в отношении общественной позиции участников видеоролика, снятого в поддержку изменений в Конституцию РФ, принятых в 2020 г. ${ }^{1}$ Присутствие в рассматриваемом видеоролике ветерана Великой Отечественной войны и содержание вышеназванного комментария позволило значительной части публичных спикеров говорить о факте оскорбления (что также привлекло внимание правоохранительных органов), которое было нанесено ветерану, и, следовательно, о проявлении неуважения к исторической памяти о Великой Отечественной войне 2 .

$P R$-технологии в ходе борьбы за симпатии населения в рамках поддержания исторического нарратива также активно используются и в других странах. Ситуация, связанная с изменением музейного статуса собора Святой Софии и возвращением статуса мечети, является ярким примером использования темы сохранения исторической памяти для реализации политических интересов. Турецкий президент Р. Эрдоган, используя существующую внешнеполитическую конъюнктуру и значительную поддержку со стороны населения $^{3}$, сумел реализовать задуманное, пойдя против решения создателя современной Турции М. К. Ататюрка о преобразовании мечети Айя-София в музей. Рассматриваемое действие позволило Р. Эрдогану объединить вокруг общей идеи как религиозные круги Турции, поддержавшие возвращение мусульманских богослужений в Айя-Софию, так и часть националистически настроенных светских турок [Аватков 2020].

Стоит отметить, что активная борьба за влияние на исторический нарратив существует в Исламской Республике Иран и в Арабской Республике Египет, в которых правящие режимы представляют, соответственно, религиозная элита в лице наиболее влиятельных иранских аятолл и египетские военные, не делающие значительного упора на религию. В обоих случаях история указанных стран и аргументы о необходимости сохранения исторической памяти (прежде всего в выгодном для правящего режима направлении) занимают значительные ресурсы власти и их основных противников - сторонников свергну-

1 Почему Навальный может себе позволить оскорбить ветерана войны. Доступ: https:// ria.ru/20200610/1572773886.html (проверено 03.07.2020).

2 Против Навального возбудили уголовное дело о клевете на ветерана. Доступ: https:// www.rbc.ru/society/15/06/2020/5ee785839a7947132bea3c53 (проверено 03.07.2020).

3 Эксперт: смена статуса Святой Софии не повлечет политические последствия для Турции. Доступ: https://tass.ru/obschestvo/8943779 (проверено 11.07.2020); Ниязбаев: давить на Эрдогана не получится, мечеть Святой Софии не станет снова собором. Доступ: https:// www.vesti.ru/video/2205044 (проверено 10.07.2020). 
того шахского режима в Иране и организации «Братья-мусульмане» в Египте [Электоральные процессы... 2018].

Оценивая описываемые процессы в контексте применения $P R$-технологий, следует подчеркнуть, что вопросы о необходимости сохранения исторической памяти, которые одновременно находятся как в сфере политического противостояния наиболее влиятельных акторов, так и в сфере национальной безопасности страны в целом, требуют постоянного участия гражданского общества в их разрешении [Родионова, Мамаева 2020]. В противном случае преобладание политических интересов над долгосрочными задачами поддержания общественной стабильности потенциально может привести к дестабилизации государствообразующих институтов, которые в отсутствие запроса общества на использование «позитивных» $P R$-технологий в части сохранения исторической памяти (освещение усилий краеведческих организаций, исторических исследований академического характера, поискового движения) со стороны политических акторов не способны в полной мере противостоять существующим угрозам в рамках данного направления.

\section{Список литературы}

Аватков В.А. 2020. Турецкая Республика. Внешняя политика: от $2002 \kappa 2018$. М.: Юрайт. 136 с.

Аникин Д.А. 2020. Память о Великой Отечественной войне как символический ресурс: особенности функционирования в религиозном сообществе. Studia Humanitatis. № 1.

Булавин А.В., Карпович О.Г., Манойло А.В., Мантусов В.Б. 2018. Мировая политика. Передовые рубежи и красные линии. М.: РИО Российской таможенной академии. $456 \mathrm{c.}$

Денисов Ю.П. 2019. Репрезентация образа Великой Отечественной войны в выступлениях В.В. Путина в начале первого срока президентских полномочий: мемориальный поворот. - Дискурс-Пи. № 2(35). С. 49-57.

Петрий П.В. 2019. Объединяющая идея России. - Военный академический жмурнал. № 1(21). С. 153-154.

Родионова М.Е., Мамаева Ю.А. 2020. Сохранение исторической памяти как важное условие социетальной безопасности. - Вопросы политологии. Т. 10. № 6(58). С. 1948-1955.

Романов А.А., Романова Л.А., Морозова О.Н. 2015. Медийный опрос как технологический прием спин-докторинговой манипуляции (на материале дискуссии опроса, проведенного 26 января 2014 года телеканалом «Дождь»). - Мир лингвистики и коммуникации: электронный научный журнал. № 42. С. 19-41.

Сталин И.В. 1938. История Всесоюзной Коммунистической Партии (большевиков). Краткий курс. М.: Политиздат. 353 с.

Цуканов Е.А., Цуканова И.В. 2016. К вопросу о возможности социокультурного проектирования больших исторических процессов. - Наука Искусство Культура. № 3(11). С. 103-107.

Электоральные процессы в России и Европе: новые практики, институты и технологии: коллективная монография (под общ. ред. М.Е. Родионовой, С.Ю. Белоконева, П.С. Селезнева, Д.А. Ежова). 2018. М.: КНОРУС. 344 с. 
MAMAEVA Yuliya Aleksandrovna, Cand.Sci. (Hist.), Associate Professor; Associate Professor of the Department of Political Science, Faculty of Social Sciences and Mass Communications, Financial University under the Government of the Russian Federation (49 Leningradsky Ave, GSP-3, Moscow, Russia, 125993; ameliya-am@rambler.ru)

RODIONOVA Marina Yevgen'evna, Cand.Sci. (Soc.), Associate Professor; Associate Professor of the Department of Political Science, Faculty of Social Sciences and Mass Communications, Financial University under the Government of the Russian Federation (49 Leningradsky Ave, GSP-3, Moscow, Russia, 125993; MERodionova@fa.ru); Director of the PR u GR Celebrium-Labs

\title{
THE USE OF PR TECHNOLOGIES AS AN EFFECTIVE TOOL FOR HISTORICAL MEMORY PRESERVING
}

\begin{abstract}
This article discusses issues related to the use of PR technologies in the course of activities related to the preservation of the historical memory of countries and the traditional views. The paper also examines the features of preventive measures by governments and other actors in relation to actions aimed at weakening the unity of public opinion on the key issues in the history of the countries under consideration. The authors carry out an analysis of the effectiveness of methods and specific actions, applicable and committed in this direction, in terms of their influence on the mentality of social groups, determined for implementation of PR technologies to preserve historical memory.
\end{abstract}

Keywords: historical memory, PR technologies, positive agenda, public consciousness, national security

ВАСИЛЕНКО Ирина Алексеевна - доктор политических наук, профессор кафедры российской политики факультета политологии Московского государственного университета им. М.В. Ломоносова (119991, Россия, г. Москва, Ломоносовский пр-кт, 27, корп. «Шуваловский»; vasilenko.irina@mail.ru)

\section{РОЛЬ ПУБЛИЧНОЙ ДИПЛОМАТИИ В РАЗОБЛАЧЕНИИ ФАЛЬСИФИКАЦИЙ ПОЛИТИЧЕСКОЙ ИСТОРИИ В УСЛОВИЯХ СОВРЕМЕННОЙ ИНФОРМАЦИОННОЙ ВОЙНЫ}

\begin{abstract}
Аннотация. В статье рассматриваются проблемы фальсификации политической истории как инструмента современной информационной войны в преддверии значимого для России исторического юбилея - 75-летия победы в Великой Отечественной войне. Автор считает, что сегодня особенно важно использовать инструменты публичной дипломатии для открытых разоблачений фальсификаций политической истории и ключевых событий Второй мировой войны с трибуны мировых политических форумов и каналов средств массовой информации. В качестве примера рассматривается реакция мировой общественности на выступление В.В. Путина на V Международном форуме памяти жертв холокоста в Израиле в январе 2020 г., где в центре внимания была роль Советского Союза и Красной армии в победе над нацизмом.

Ключевые слова: фальсификация политической истории, публичная дипломатия, историческая память, символический капитал культуры

